\title{
Lever for recording fish target bumping
}

\author{
ALLEN H. WOLACH and PETER ROCCAFORTE \\ Illinois Institute of Technology, Chicago, Illinois 60616
}

\begin{abstract}
A method for constructing a lever to record fish target bumping is described. The lever has a pivot assembly that is submerged in a fish chamber. A photoelectric system is activated when a target is moved. The lever requires very little force. Force requirements and the distance that the lever travels can be changed easily.
\end{abstract}

Leverpressing (target bumping) for fish is usually monitored by a transducer-amplifier system. Typically the target is cemented to a thin rod attached to a crystal phonograph cartridge. The output from the cartridge goes to an amplifier-integrator circuit that terminates in a relay (e.g., Bitterman, 1966; Holmes \& Bitterman, 1969; Woodard \& Bitterman, 1974). The relay produces discrete pulses that can be used to operate relay components or transistorized logic units. The phonograph cartridge/amplifier/integrator system can be adjusted so that the relay can be operated by bumps with very little force (impulse) on the paddle. In fact, the circuit can be used to monitor acitivity (waves) when the fish is separated from the paddle by a wire screen.

The phonograph cartridge/amplifier/integrator system has several disadvantages. First, the amplifier-integrator is relatively expensive. Second, the amplifier circuit is not completely stable. Consequently, the controls on the amplifier have to be reset. Sometimes the circuit starts to operate on its own and may lead to reinforcements that are not related to a fish's response pattern. The amplifier is more likely to fire the relay on its own in applications in which maximum sensitivity is required. Solid state versions of the circuit (Holmes \& Bitterman, 1969; Woodard \& Bitterman, 1974) are somewhat sensitive to noise from other components. Third, the phonograph cartridge is sensitive to impulses rather than duration of bump. That is, the phonograph cartridge does not produce an output for the duration of a bump, but produces an output that fires the circuit when the phonograph cartridge first produces enough voltage to activate the amplifier-integrator (i.e., the phonograph cartridge is a velocity transducer). The cartridge/ amplifier/integrator cannot be used to record the duration of a bump in a study in which bump durations of different lengths are differentially reinforced. In addition, the cartridge/amplifier/integrator circuit reinforces a response topography (hard quick bumps) that is not analogous to the response topography in rat leverpressing studies (especially if the offset of a rat's response operates the programming apparatus).

Requests for reprints should be sent to Allen H. Wolach. Department of Psychology, Illinois Institute of Technology, Chicago, Illinois 60616
The goldfish lever described here overcomes some of the disadvantages of the phonograph cartridge/amplifier/ integrator. The lever is constructed from Plexiglas for less that $\$ 10$ (including the photoelectric-relay system), and it is in the same sensitivity range as the cartridge/ amplifier/integrator system. The lever consists of a paddle-pivot system with the pivot very close to the paddle. A long flag (piece of thin Plexiglas) is attached to the assembly so that a very small movement of the paddle produces much greater movement at the top of the flag. The flag is used to interrupt a light beam directed at a photocell. The photocell controls a sensitive relay which stays on for the amount of time that the flag is displaced from the neutral position. The flag assembly is light enough so that responses with very little force can activate the paddle. A stainless steel rod $(.1 \mathrm{~cm}$ diam $)$ is used as the pivot. The pivot assembly is submerged in the water of the fish chamber. Water in the chamber serves to lubricate the pivot and increase the sensitivity of the lever.

\section{HARDWARE AND METHOD}

Figures 1 and 2 show the complete lever mounted on a stand (Figure 1) and the paddle-pivot support system (Figure 2). Figure 2 shows that the paddle (A) is bonded to the pivot holder (B), which is bonded to the flag (E). A small hole $(.1 \mathrm{~cm}$ in diam and $.2 \mathrm{~cm}$ deep) is drilled in the top of the pivot holder before the flag is bonded. A stainless steel rod $(D, .1 \mathrm{~cm}$ diam and $.8 \mathrm{~cm}$ high) is cemented in the hole. Washers can be placed on the rod to increase the force that must be exerted on the paddle. A paddle guide $(\mathrm{H})$ is bonded to the bottom support (I). The pivot holder $(B)$ with the bonded flag $(E)$ is placed between the bottom support with the bonded paddle guide $(\mathrm{H}, \mathrm{I})$ and the side piece $(G)$. The pieces (G, E. B, H, and I) are clamped together and the hole for the pivot assembly is drilled through all of the pieces. The pivot hole $(.12 \mathrm{~cm})$ is slightly larger than the pivot $(.1 \mathrm{~cm})$. After the hole is drilled, the components are separated and the stainless steel pivot $(.1 \mathrm{~cm}$ wide and $1.0 \mathrm{~cm}$ long) is centered in the pivot holder (B). The right half of Figure 2 shows the manner in which the front (T) and back (U) pivot assembly pieces are bonded to the bottom (I) and side supports $(\mathrm{G})$ to hold the paddle-pivot assembly in place. There should be enough room between the paddle guide $(H)$ and the side support (G) for the paddle-pivot assembly (E, B) to move freely. The top of the flag. which is $22.0 \mathrm{~cm}$ above the pivot, is painted black to break the beam of light in the photoelectric assembly.

Figure 1 shows the adjustable stops mounted to limit move- 


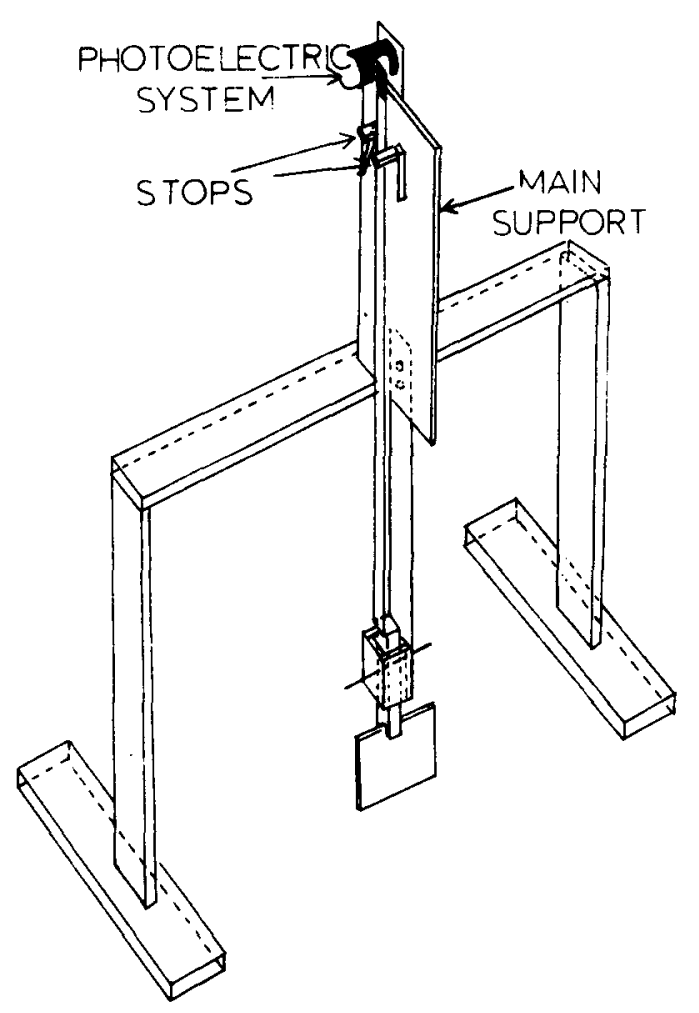

Figure 1. Completed lever mounted on a stand.
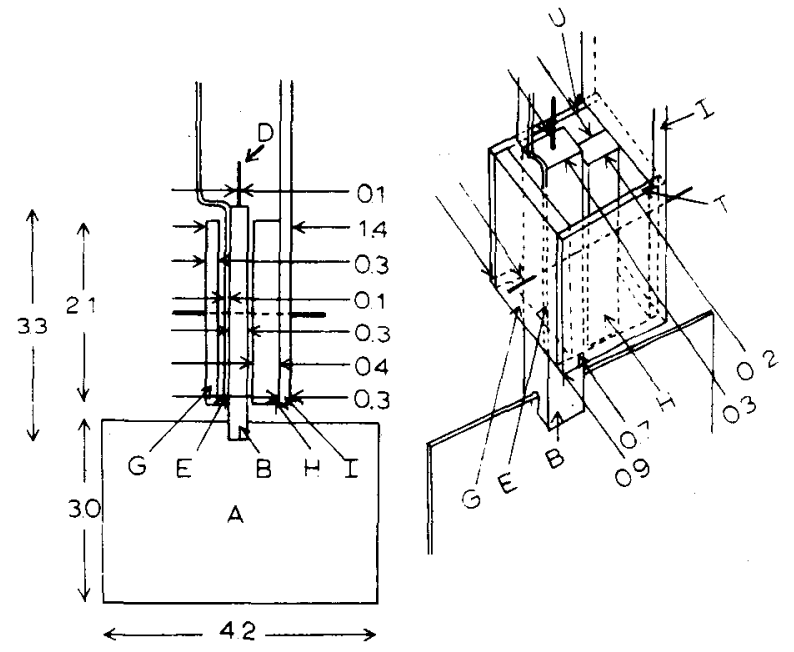

Figure 2. Paddle-pivot support system.

ment of the flag. Figure 3 is a circuit for a photoelectric assembly to control a relay. The transformer (T1) supplies $27 \mathrm{~V}$. The voltage is half wave rectified by the diode (D1, 1N 4279) and filtered by a capacitor $(\mathrm{Cl}, 50 \mathrm{mft}$ at $50 \mathrm{~V})$. The photocell (PH1, GE A33) switches the sensitive relay (RY1, Potter \& Brumfield RS5D) on and off. Resistor R1 (220 ohms) lowers the voltage from the transformer to operate the light (L1,

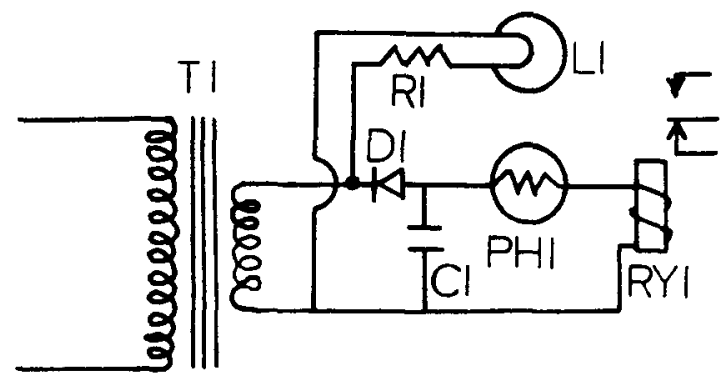

Figure 3. Schematic diagram of photoelectric relay system. See text for description of components.

Chicago miniature CM8-661). The relay contacts are used to control relay or solid state programming apparatus.

The lever is adjusted while the pivot is under water in the fish chamber. First, the bottom support (I in Figure 2) is moved back and forth until the flag always returns to rest on the back stop. Then the bottom support is secured to the main support with a machine screw. The stops (Figure 1) are adjusted so that the flag travels an appropriate distance (e.g., $.2 \mathrm{~cm}$ ) when the paddle is pushed. The photoelectric system is rotated so that the flag does not interrupt the light beam when it rests on the back stop. When the top of the flag moves an appropriate distance (e.g., $.2 \mathrm{~cm}$ ), it interrupts the light beam and continues to interrupt the beam if the paddle is pushed until the flag hits the front stop.

The fish lever, like a rat lever, produces contact closure (relay closure) when it is moved an appropriate distance. The lever continues to produce the contact closure if the target is pushed an even greater distance.

The lever works best in a target bumping situation when it is mounted so that the pivot is very low in the water. This prevents waves (usually greatest near the top of the water) from activating the lever. When the lever is separated from the fish by screening, e.g., in monitoring activity, the lever should be placed higher in the water; the pivot must remain submerged. The lever is less likely to detect artifacts from wave motion (as compared with a phonograph cartridge/amplifier/integrator system) because it detects motion in only one direction. The lever also allows the experimenter to keep force requirements relatively constant across a wide range of travel (distance the lever must be moved).

\section{REFERENCES}

Bitterman. M. E. Animal behavior. In J. B. Sidowski (Ed.), Experimental methods and instrumentation in psychology. New York: McGraw-Hill, 1966.

Holmes, N. K., \& Bitterman, M. E. Measurement of consummatory behavior in the fish. Journal of the Experimental Analysis of Behavior, 1969, 12, 39-41.

Woodard. W. T., \& BitTerman, M. E. Improved techniques for the measurement of consummatory behavior in fishes. Behavior Research Methods \& Instrumentation, 1974, 6, 321-324.

(Received for publication April 1. 1976; revision accepted June 10, 1976.) 